\title{
Target Strength Measurements and Modeling of Walleye Pollock and Pacific Hake
}

\author{
Kouichi Sawada, ${ }^{* 1}$ Zhen Ye, ${ }^{* 2, \dagger}$ Robert Kieser, ${ }^{* 3}$ Gordon A. McFarlane, ${ }^{* 3}$ \\ Yoichi Miyanohana, ${ }^{* 1}$ and Masahiko Furusawa ${ }^{* 4}$ \\ ${ }^{*}$ National Research Institute of Fisheries Engineering, Ebidai, Hasaki, Kashima, \\ Ibaraki 314-0421, Japan \\ ${ }^{*}$ Institute of Ocean Science, Sidney, Canada \\ ${ }^{* 3}$ Pacific Biological Station, Nanaimo, B. C., Canada \\ ${ }^{*}$ Tokyo University of Fisheries, Konan, Minato, Tokyo 108-0075, Japan
}

(Received June 16, 1998)

This paper reports a laboratory target strength (TS) measurement and theoretical modelling of walleye pollock and Pacific hake. The measurements are performed in a tank as a function of fish tilt angle, which is controlled in one-degree steps. A precision echo sounder is used and sphere calibrations are conducted before or after the measurement. A specialized soft X-ray imaging system is used to map the fish swimbladder. The $\mathrm{X}$-ray images are digitized to obtain the fish morphological parameters. Based on these parameters, theoretical TS of the fish is calculated using the approximate deformed cylinder model and the general prolate spheroid model. An advantage of using these models lies in their simplicity and the fact that few parameters are required in the model computation. Calculations indicate a negligible contribution of the fish body to the total scattering in the wide range of tilt angle. The theoretical TS values are compared with the measured values. Agreement between measured and theoretical TS is reasonably good for near normal incidence, but deteriorates for larger tilt angles. The level of agreement is discussed. Obtained maximum and average TS values are nearly equal to or a little bit smaller than the published data. Using the deformed cylinder model, broad band TS characteristics are generated. Our results highlight the usefulness of the simple method to predict fish TS using the deformed cylinder model associated with X-ray imaging.

Key words: target strength of fish, controlled measurement, spheroid model, deformed cylinder model, soft X-ray image, walleye pollock, Pacific hake

A good understanding of fish target strength (TS) is essential for the reliable interpretation of acoustic data from fish stock assessment surveys and biological studies. The need for a better knowledge of fish TS has been recognized for many years and has been emphasized. Review of fish TS measurements can be found in MacLennan and Simmonds. ${ }^{1)}$

Nakken and Olsen ${ }^{2)}$ reported important early measurements of fish TS on four species of stunned or dead specimens, using two frequencies. Similar but more sophisticated measurements were conducted by Foote and Ona ${ }^{3)}$ and by Miyanohana et al ${ }^{4)}$ Measurements of live, caged fish ${ }^{5,6}$ threw light from another aspect. The TS information from stunned or caged fish is complemented by in situ measurements. ${ }^{713)}$ The latter have the advantage that the fish are observed and measured in their natural environment. However, it is not easy to relate individual echoes with individual fish; hence size, species, and other characteristics of the scatterer are rarely known.

Significant progress in theoretical modeling of fish TS has been made by Foote ${ }^{14)}$ using the Kirchhoff approximation to calculate TS at rather high frequencies, by Furusawa ${ }^{15)}$ modeling fish swimbladder and body as prolate spheroids, and by Stanton ${ }^{16,177}$ proposing the finite cylinder models. Recently, Clay and Horne $\mathrm{e}^{18\}}$ and Ye and Furusawa ${ }^{19}$ used high frequency approximations to develop simple deformed cylinder TS models. The finite cylinder model has further elaborated using the Kirchhoff integral. $^{20,21)}$

The comparison of experimental data with TS model predictions has been encouraging (e.g. Foote; ${ }^{14)} \mathrm{Clay}$ and Horne $\left.^{18}\right)$, and does much to alleviate concerns noted by Nakken and Olsen:2) "Due to the complexity of factors governing the reflection of sound from fish, it is impossible to calculate the scattered sound field. Thus the relationships between TS and fish parameters (i.e. species and size) have to be established empirically".

Use of the same fish for TS measurements and model calculations provides a basis for closer comparison of results. It also provides feedback that may lead to further improvements in TS models. This paper presents such a comparison for two marine species: walleye pollock Theragra chalcogramma and Pacific hake Merluccius productus. The former is important to Japanese fisheries and the latter to Canadian West Coast fisheries. Both countries share common concerns in marine fisheries management and pool resources to solve these problems.

TS and swimbladder shape measurements for modeling

\footnotetext{
${ }^{\dagger}$ Present address: Department of Physics, National Central University, Taiwan, R.O.C.
} 
are made on the same fish. Dorsal aspect TS of walleye pollock and Pacific hake are measured at $38 \mathrm{kHz}$ in a tank on specimens caught by hook and line or by trawl and frozen. Soft X-ray imaging is used to obtain the shapes of the swimbladder for modeling. We use the vacant prolate spheroid model (PSM) ${ }^{15)}$ and the new deformed cylinder model $(\mathrm{DCM})^{20,21)}$ to compare theoretical predictions and measurement. An advantage of these models is their reliance on fewer morphological parameters, which are often hard to obtain. In addition, McClachie et al. ${ }^{22)}$ have shown that the DCM, which is simpler ${ }^{19)}$ than what we use in this paper, is a moderate approximation method, providing average TS with accuracy between the Kirchhoff approximation and other solutions.

The purpose of this paper is

1) to establish or examine the simple method of TS or its pattern prediction, without acoustical measurement, using model(s) whose parameters are provided by X-ray image of the swimbladder,

2) to examine how well the TS theoretical models, especially newly developed DCM, predict TS patterns,

3) to get values of maximum TS and average TS for walleye pollock and hake and compare them with the published data in order to add new knowledge for TS of these two species, and

4) to see TS characteristics by modeling at a broader range of frequencies than the experimentally usable frequency.

The following two points should be noted. The hake is difficult to catch in good condition for TS measurement and this is the first time to measure Pacific hake TS by a controlled method. Also, it is the first time to apply the new $\mathrm{DCM}^{21)}$ to predict the backscattering pattern of actual fish.

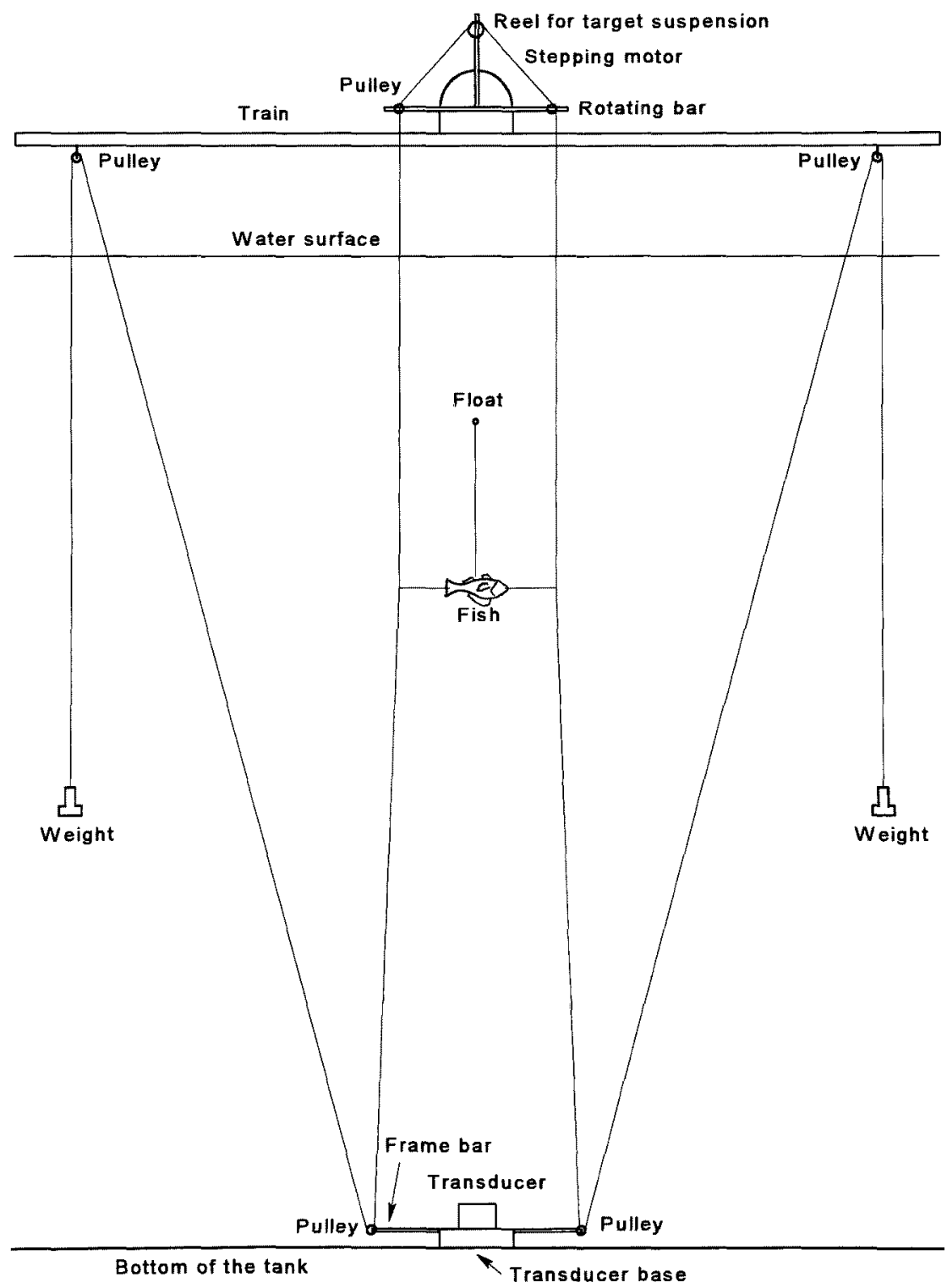

Fig. 1. Suspension system for fish specimen and standard sphere.

Standard sphere is suspended from the center of rotating bar at about the same depth of specimen at the calibration time. 


\section{Materials and Methods}

\section{Experimental Set-Up}

The X-ray and TS measurements were carried out December 1994 at the National Research Institute of Fisheries Engineering (NRIFE), Japan. A $10 \mathrm{~m}$ depth $\times 10 \mathrm{~m}$ width $\times 15 \mathrm{~m}$ length indoor tank was used for the TS measurement. The tank was filled with fresh water just prior to use. Marine fish are better measured in seawater, but using seawater in a large tank was difficult. The fact that most of the scattered energy originated from the swimbladder permits freshwater use. This point is further discussed in "Discussion".

The target suspension system is shown in Fig. 1. This configuration follows, with some modifications, Nakken and Olsen ${ }^{2)}$ and Miyanohana et al. ${ }^{4)}$ Small hooks are attached to the fish snout and tail, and thin horizontal nylon lines locate the specimen between the vertical suspension lines. The tops of these lines are connected to the two sides of a rotating bar that is mounted on the axis of a stepping motor. The vertical lines are tensioned by a simple weight and pulley system. A small float is used to keep the fish in an upside down position. This provided dorsal aspect alignment with respect to the transducer that is mounted on the tank floor below the fish. A standard sphere, a $60 \mathrm{~mm}$ diameter copper sphere, ${ }^{23)}$ is suspended at about the same depth of the specimen before or after the measurement for the calibration. The distances between the transducer, specimen, and weight are large enough to avoid interference. The separation between the transducer and specimen is about eight meters, sufficient to satisfy a far field condition. ${ }^{24}$ Additional details about the experimental setup are given in Miyanohana et al. ${ }^{4)}$ and Sawada et al. ${ }^{25}$ )

\section{Instrumentation and Data Recording}

The versatile echo-sounding system (VESS) ${ }^{26)}$ and a split beam transducer were used to insonify the fish. The transducer transmits pulses and receives the echoes from the on-axis fish. The hardware TVG was removed to obtain accurate echo waveforms. The range compensation was in corporated in the analysis. The specifications of the sounding system are presented in Table 1.

The sonar equation was used to relate the echo peak amplitude, $V$, to $T S$ :

$$
20 \log V=K-40 \log r-2 \alpha r+T S .
$$

The calibration constant $K$ is obtained by measuring echoes from the standard sphere before or after the measurement. Range, $r$, is determined from the echo delay and fresh water absorption loss, $2 \alpha r$, is negligible. The beam factor is omitted as fish or a sphere is on axis.

The echo shape and voltage were monitored and record-

Table 1. Specifications of the acoustic system

\begin{tabular}{ll}
\hline Frequency & $38 \mathrm{kHz}$ \\
Transducer beam width & $6.2^{\circ}$ \\
Source level & $223 \mathrm{~dB}$ re $\mu \mathrm{Pa}$ at $1 \mathrm{~m}$ \\
Pulse repetition period & $213 \mathrm{~ms}$ \\
Pulse width & $0.6 \mathrm{~ms}$ \\
Receiver bandwidth & $2.5 \mathrm{kHz}$ \\
\hline
\end{tabular}

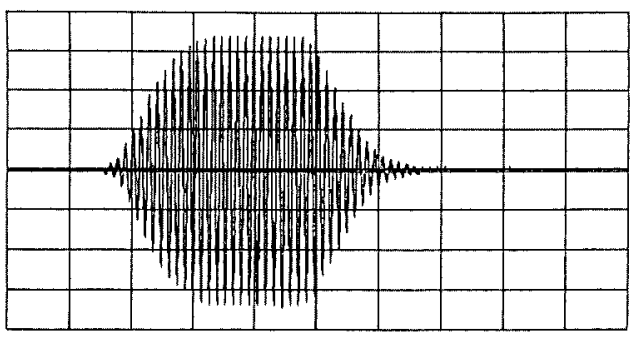

(a)

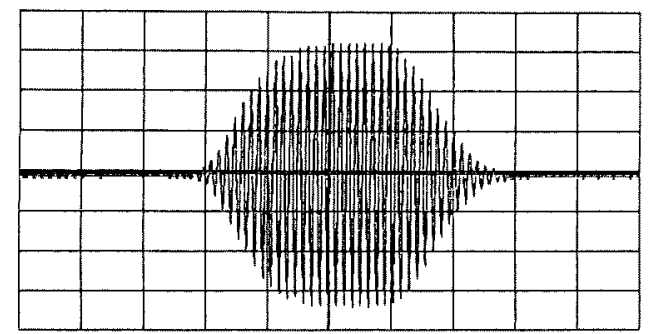

(b)

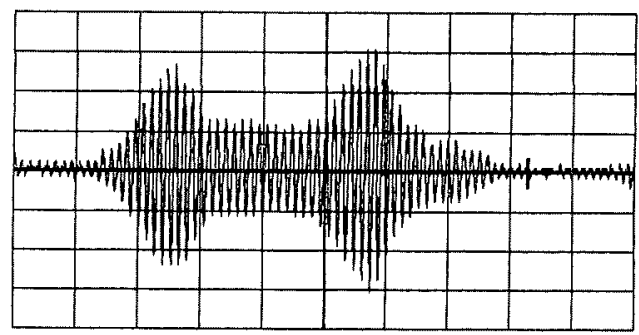

(c)

Fig. 2. Observed echo shapes (a) from a $60 \mathrm{~mm}$ diameter $\mathrm{Cu}$ standard sphere, (b) from Pollock 4 at tilt angle $13^{\circ}$ (normal echo shape) and (c) from Pollock 4 at $-43^{\circ}$ (deformed shape).

Horizontal scale is $0.2 \mathrm{~ms} / \mathrm{div}$, vertical scales are $2.85,2.5$ and $0.275 \mathrm{~V} /$ div, respectively.

ed with a digital oscilloscope (LeCroy 9304 AM). A typical echo from the copper sphere is shown in Fig. 2(a) and a typical fish echo at near dorsal aspect is shown in Fig. 2(b). Distorted echoes are often observed at large tilt angles as shown in Fig. 2(c), however TS measurements are still based on peak echo amplitude.

We measured the amplitude when the echoes on the oscilloscope become stable after several pings for each fish aspect or tilt angle. Aspect angles ranged from $-50^{\circ}$ to $+50^{\circ}$ (head down to head up aspect) and were incremented by $1^{\circ}$. All TS measurements are based on single beam echo data. The split beam capability was only used to assure the accurate location of the specimen on the acoustic axis.

\section{The Fish}

Two fish species were examined. Walleye pollock Theragra chalcogramma and Pacific hake Merluccius productus. Walleye pollock specimens were obtained in the summer of 1994 as part of a Bering Sea pollock survey. They 


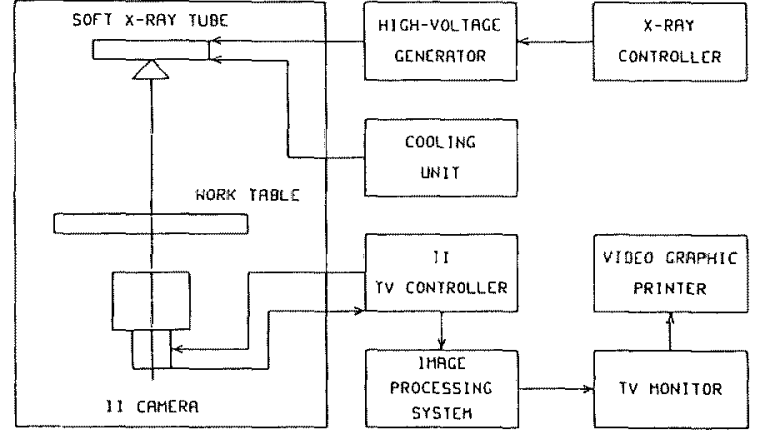

Fig. 3. System block diagram of X-ray imaging system (Softex PROTEST 100) that was used to obtain the fish swimbladder images.

were caught on hook and line at a depth about 40 to 50 meter in a sheltered inlet of Unalaska Island. The fish were kept alive in a tank on board for more than 24 hours. They then were killed by a blow to the head to establish the original swimbladder shape and then frozen at approximately $-35^{\circ} \mathrm{C}$. Pacific hake were caught in May 1994, by midwater trawl at about a 90 meter depth off Vancouver Island, British Columbia. ${ }^{27)}$ The fish were frozen after catch and shipped to Japan. Then, the fish were transported to Hasaki in a cool condition by car.

Both pollock and hake were kept frozen at low temperatures in the laboratory. Four pollock and two hake, all in visibly good condition, were chosen. The fish were thawed in ice water over a 24-hour period. X-ray measurements were performed to obtain swimbladder outlines for side and dorsal aspects. The block diagram of the X-ray analyzing system (Softex PRO-TEST 100) is shown in Fig. 3. The fish were tethered and submerged for TS measurements. The X-ray and TS measurements were completed in less than ten hours. In some cases X-ray measurements were repeated after the TS measurements to look for possible swimbladder changes.

\section{The Models of Sound Scattering by Fish}

We have chosen to use the vacant PSM $^{(5)}$ and the $\mathrm{DCM}^{21)}$ to interpret and extrapolate the experimental results. Although PSM is generally unable to account for the detailed swimbladder shape, since it is exact in general solutions, it can provide guidance for other models. Also from its general properties, it can provide general trends of scattering by marine animals. The DCM, on the other hand, uses a series of short cylinders to achieve a better description of the swimbladder shape and model computations are relatively simple. It has been shown that the DCM can produce results that are in reasonable agreement with the exact PSM. ${ }^{21)}$

Among the many parts of a fish, the swimbladder is conjectured as the dominant scatterers. Later computation based on the DCM will show that contributions from the fish body are negligible. This is consistent with published results, ${ }^{14,15,28,29)}$ and with a general theoretical study by $\mathrm{Ye}$ and Farmer. ${ }^{30)}$ Therefore, the vacant PSM and gaseous DCM are mainly used for the swimbladder and the liquid DCM is used to examine the contribution from fish body.

The PSM approximates the swimbladder by a spheroid. The spheroid has rotational symmetry about its major axis

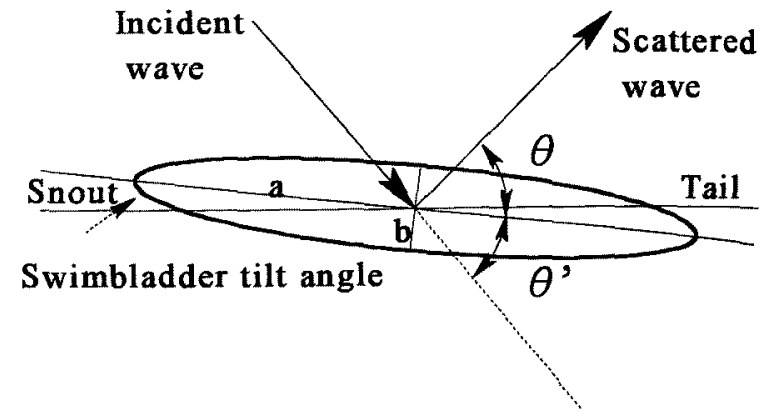

Fig. 4. Swimbladder geometry for the soft spheroid model.

The direction of the incident and scattered waves and the fish tilt angles are indicated. Positive angles are head up.

and has a soft body. The scattering function is in terms of spheroidal wave functions in the far field approximation: ${ }^{15)}$

$$
\begin{aligned}
f\left(\theta, \phi \mid \theta^{\prime}, \phi^{\prime}\right)= & -\frac{2 i}{k} \sum_{m=0}^{\infty} \sum_{n=m}^{\infty} \frac{\varepsilon_{m}}{N_{m n}(h)} S_{m n}\left(h, \cos \theta^{\prime}\right) \\
& \times A_{m n} S_{m n}(h, \cos \theta) \cos m\left(\phi-\phi^{\prime}\right)
\end{aligned}
$$

where $h \cong k q$ ( $k$ is the wave number of the surrounding medium, and $2 q$ is the distance between focal points), $\theta, \phi$ and $\theta^{\prime}, \phi^{\prime}$ are the spherical angle coordinates of the scattered and incident wave respectively, $\varepsilon_{m}$ is the Neumann factor, $S_{m n}$ is the prolate spheroidal angle wave function of the first kind of order $m$ and degree $n$, and $N_{m n}$ is its norm. The coefficients $A_{m n}$ are determined by applying appropriate boundary conditions.

The TS of a scatterer is defined as,

$$
T S=10 \log \left(\left|f_{b s}\right|^{2}\right)
$$

where $f_{b s}$ is the backscattering function obtained by setting $\theta=\pi-\theta^{\prime}, \phi=\phi^{\prime}-\pi$ (see Fig. 4).

A DCM for an elongated scatterer was first studied by Junger $^{31)}$ and later improved by Stanton. ${ }^{16,17)} \mathrm{Ye}$ and Furusawa ${ }^{19)}$ derived a simple high frequency expression. They have shown that the sound scattering from an elongated deformed-cylinder can be approximated by superimposing the scattered waves from a series of small, adjacent cylindrical elements that are embedded in an infinite cylinder. The DCM is further improved introducing Kirchhoff integral for scattering elements. ${ }^{20,21)}$

The resulting scattering function $f$ is given by

$$
\begin{aligned}
f\left(\boldsymbol{k}_{i}, \boldsymbol{k}_{s}\right)= & \int \frac{-i}{\pi} \sum_{n=0}^{\infty} B_{n}(z) F_{n}(z)(-i)^{n} \cos [n \phi(z)] \\
& \times \exp \left[i \boldsymbol{k}_{i} \cdot \boldsymbol{r}(z)-i \boldsymbol{k}_{s} \cdot \boldsymbol{r}(z)\right] d z
\end{aligned}
$$

where the integration is done along the deformed cylinder axis, $z, \boldsymbol{k}_{i}$ and $\boldsymbol{k}_{s}$ are incident and scattered wave vector respectively, $i=\sqrt{-1}, B_{n}(z)$, and $F_{n}(z)$ are $n$-th order expansion coefficients including element radii which generally changes along the axis, and incident and scattering angles, etc., $\phi(z)$ is the azimuthal angle between the incident and scattering directions, the exponential term depicts phase shift, and $r(z)$ is range from the reference point. The details can be referred to Ye et al. $^{21)}$ and the experimental verification is seen in Ding and Ye. ${ }^{32)}$ This expression is rel- 
atively simple and can be easily programmed. This model can be applied to almost all materials including a gaseous body such as the swimbladder and liquid body such as a fish body. The peculiar limitation of this model is that the aspect ratio should be large (approximately $>5$ ) and that the tilt angle should not be too large $\left(<40^{\circ}\right)$. These limitations, however, are considerably relaxed compared with the traditional finite cylinder models. ${ }^{33)}$ Our calculations are within these limitations. Estimation of the required swimbladder measurements will be discussed in the next section.

The fish body is approximated as a liquid-filled slender scatter. The reason why the fish body is modeled as liquidfilled instead of elastic material-filled are two-fold. One is that the shear properties due to the elasticity in fish flesh are usually unavailable. Second, there exist studies that support the liquid model. For example, in $\mathrm{Ye}$ and Farmer ${ }^{30}{ }^{3}$ such a model has been used to study acoustic attenuation by different types of fish, and the results compare reasonably well with some published data (e.g. Furusawa et al. ${ }^{34)}$ ).

In our computation we use the following parameters: the sound speeds in fresh water, in seawater, in the swimbladder, and in the fish body are taken as 1482, 1522, 340, and $1560 \mathrm{~m} / \mathrm{s}$, respectively; the density ratios between air and fresh water, between air and seawater, and between fish flesh and fresh water, are taken as 0.00129, 0.001259 and 1.04. These numbers are within the range widely accepted. ${ }^{24)}$

\section{Maximum and Average TS}

The maximum TS is easily read as the peak value in the TS pattern, which is defined as the TS function against fish tilt angle. The most reasonable definition of the average TS is that given by Foote, ${ }^{35}$ followed by Miyanohana et al. ${ }^{4)}$ The TS pattern is averaged for a normal distribution of tilt angle described by an average tilt angle and a standard deviation pair; for example, $(-5,15)$ means a mean tilt of $5^{\circ}$ head down and standard deviation of $15^{\circ}$. The maximum and averaged TS are derived for measured and modeled patterns and the results are compared. If the standard deviation of tilt angle is large and beam width is not too small, as in the present case, the average TS dose not vary much with the average tilt angle. ${ }^{36}$ Therefore, the obtained average TS can be referred to for actual use.

One of the merits of modeling is the ability to predict some characteristics purely by calculation. We calculate TS patterns for wide range of frequency using DCM and deduce maximum and average TS for the frequency range.

It is convenient and reasonable to normalize the TS value by length squared; when the length is in centimeter the normalized TS in decibel is shown as $T S_{c m}$.

\section{Results}

Figure 5 illustrates typical soft X-ray images of the side aspect of the swimbladder of Hake. The tail to head orientation is from right to left. The backbone and swimbladder are visible. The unprocessed or live image is compared with three image enhancement procedures.

Dorsal and side aspect swimbladder outlines are drawn from the soft X-ray images. Figure 6 gives the dorsal and
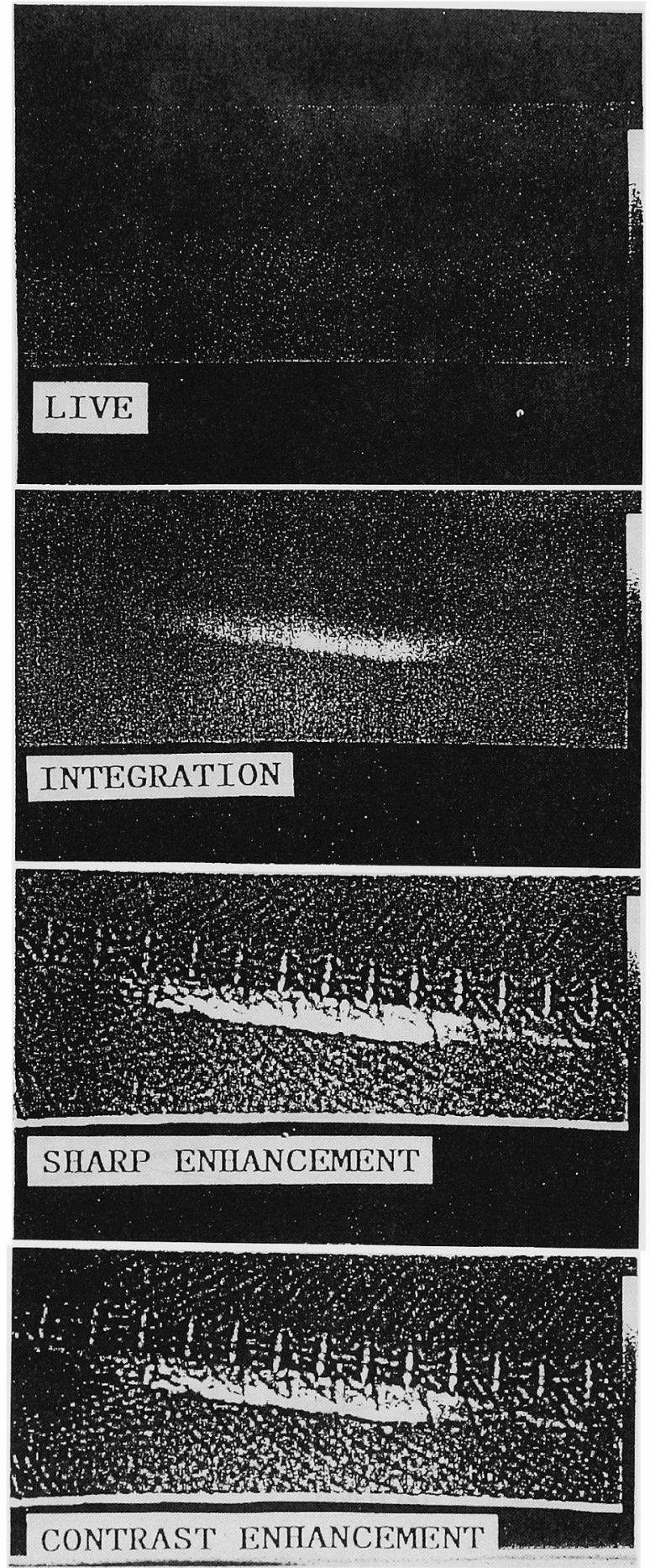

Fig. 5. Side aspect soft X-ray swimbladder image.

Three image processing procedures are compared with the live image. The fish head is to the left. Backbone, spine and swimbladder are visible.

side aspect swimbladder outlines for the six specimens. The X-ray images of dorsal shape for Pollock 3 were viewed but failed to record the whole shape of swimbladder, so that the heights in the side view were used for the widths. The six swimbladder outlines are quite different. This reflects natural swimbladder variability between fish, 

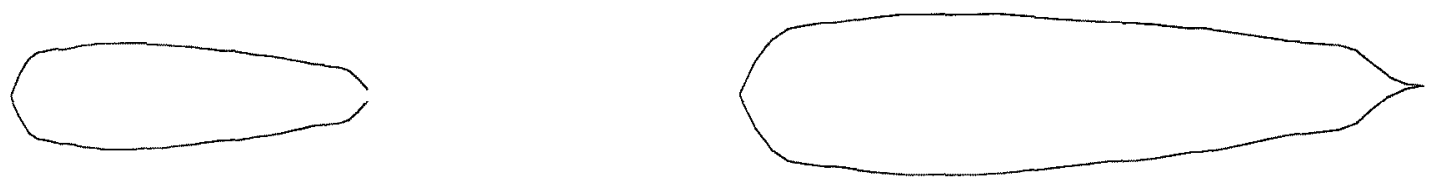

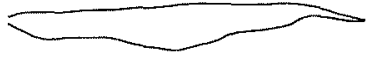

(a) Pollock 1
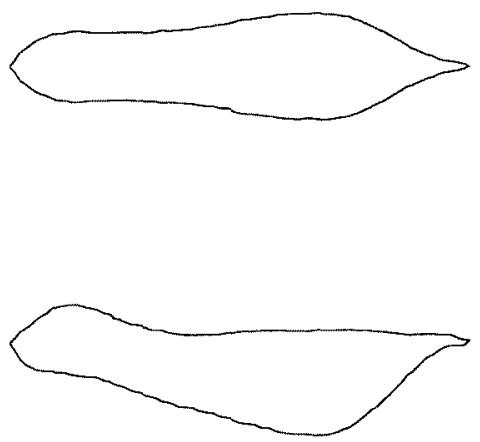

(c) Pollock3
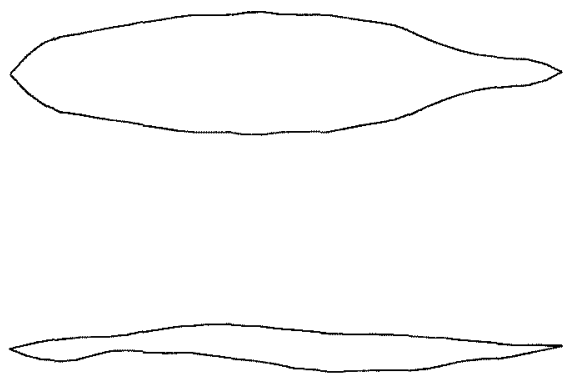

(e) Hake 1

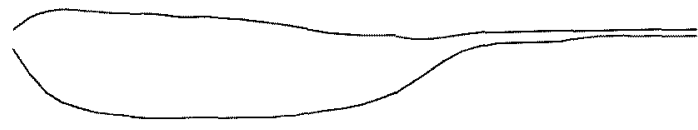

(b) Pollock2
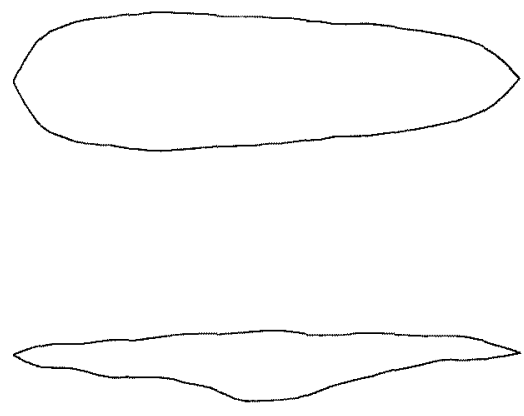

(d) Pollock4
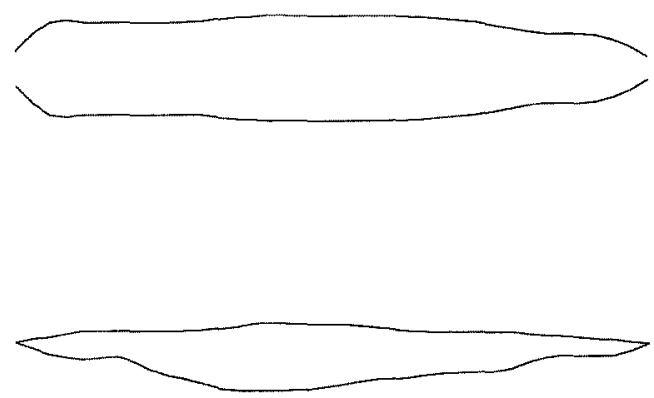

(f) Hake2

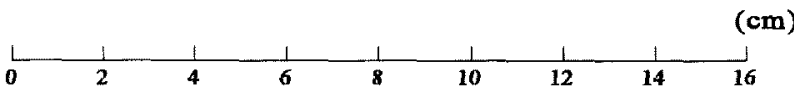

Fig. 6. Swimbladder outline drawn from $X$-ray images.

The dorsal and side aspect (upper/lower outline) are shown for each specimen. Dorsal outline of Pollock 3 could not be obtained and is estimated from the side outline assuming the width is equal to the height at the same section.

distortions caused by our fishing and specimen preparation, and difficulties in reading the X-ray images. X-ray images taken before and after thawing indicate that this proc- ess does not substantially affect the general shape and volume of the swimbladders.

Figure 7 shows, as an example for Pollock 2, how swim- 

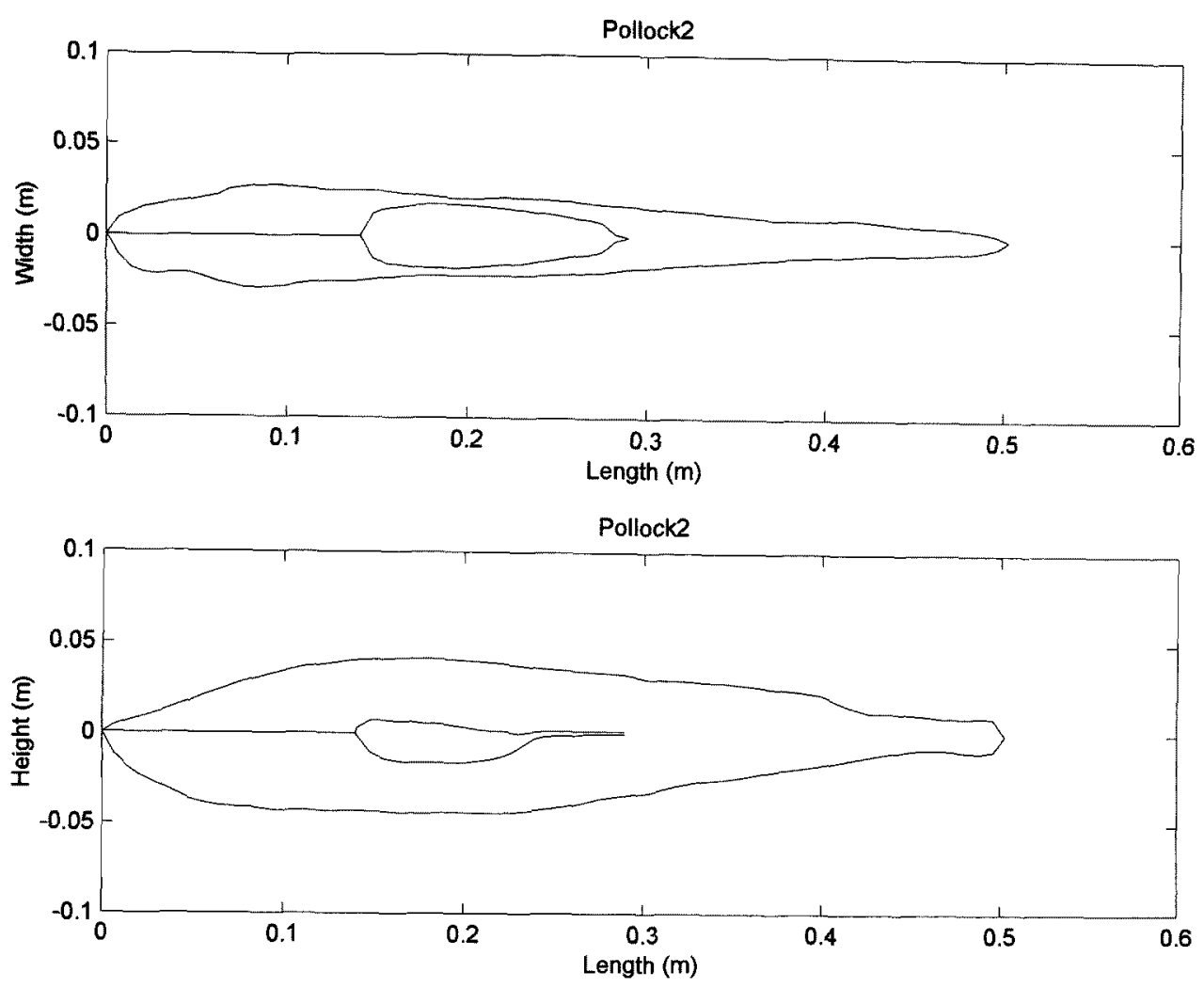

Fig. 7. Typical dorsal aspect and side aspect body and swimbladder outline drawn from soft X-ray images (Pollock 2).
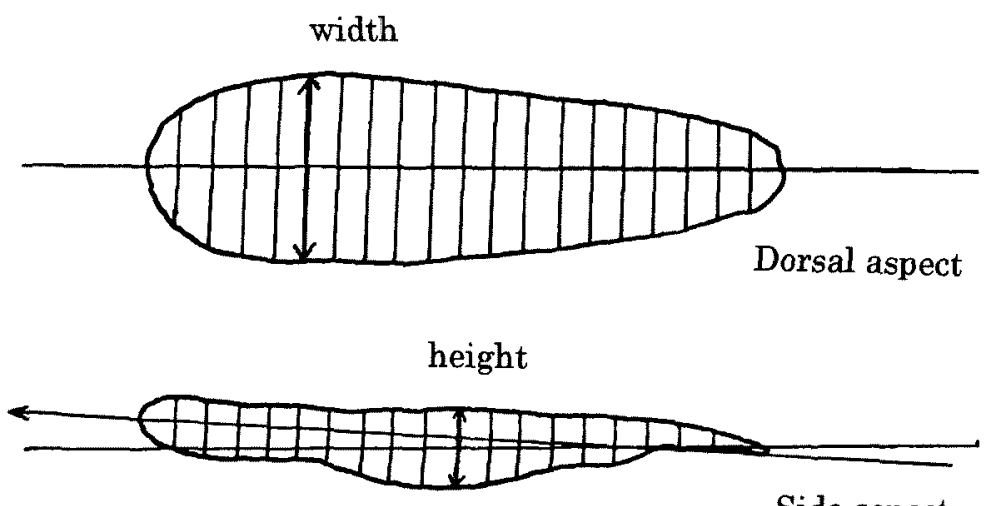

Side aspect

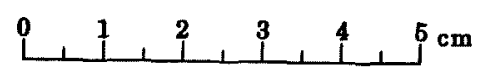

Fig. 8. Typical dorsal and side aspect swimbladder outline drawn from soft X-ray images (Pollock 1).

The short perpendicular lines to the swimbladder axis align the cylinders that are used to model the swimbladder.

bladders are positioned in the body. The contribution from the body is considered later using this example.

Figure 8 presents the swimbladder outline from Pollock 1 as another example. The horizontal lines indicate the fish axis (snout to tail). The arrow shows the major swimbladder axis defined in the side aspect. The arrow points towards the head. Lines perpendicular to the swimbladder axis define the heights and widths of the cylinders that are used by the DCM.

The larger length of the swimbladder shown in the dorsal and side aspect image is used for the length in both models. The width or minor diameter for the PSM is given by the average of width and height at the point of maximum width. The cylinder diameters are given by the average of width of the dorsal aspect and height of the side aspect of swimbladder outlines as shown in Fig. 8. Their 
Table 2. Fish and swimbladder size measurements

\begin{tabular}{|c|c|c|c|c|c|c|c|c|c|c|}
\hline Spec. & $\begin{array}{c}\text { Weight } \\
\mathrm{g}\end{array}$ & $\begin{array}{c}\text { Length } L \\
\mathrm{~mm}\end{array}$ & $\begin{array}{c}2 a \\
\mathrm{~mm}\end{array}$ & $\begin{array}{c}2 b \\
\mathrm{~mm}\end{array}$ & $2 a / L$ & $b / a$ & $\begin{array}{c}\text { Angle } \\
\text { deg }\end{array}$ & Slices & Year & Condition \\
\hline \multicolumn{11}{|l|}{ Pollock } \\
\hline 1 & 340 & 336 & 78.2 & 16.5 & 0.23 & 0.21 & 3 & $19 \times 2$ & 1994 & deflated \\
\hline 2 & 1,032 & 559 & 149.3 & 28.8 & 0.27 & 0.19 & 0 & $20 \times 2$ & 1994 & good \\
\hline 3 & 1,164 & 611 & 100.9 & 23.3 & 0.17 & 0.23 & 5 & 88 & 1994 & good \\
\hline 4 & 820 & 518 & 111.0 & 22.9 & 0.21 & 0.21 & 5 & $19 \times 2$ & 1992 & deflated \\
\hline \multicolumn{11}{|l|}{ Hake } \\
\hline 1 & 681 & 458 & 121.0 & 17.6 & 0.26 & 0.15 & 7 & $16 \times 2$ & 1994 & deflated \\
\hline 2 & 794 & 499 & 138.1 & 18.7 & 0.28 & 0.14 & 6 & $18 \times 2$ & 1994 & good \\
\hline
\end{tabular}

The column leading is explained in the text.

vertical position relative to the swimbladder axis is determined from the side aspect image as the center between the upper and lower swimbladder walls.

Except for Hake 2 it was difficult to map the exact geometry from the X-ray images as the tail end of the swimbladder tapers and is often hidden by the backbone. Most dorsal aspect images are more difficult to interpret than side aspect images. The deflated swimbladders found in Pollock 1 and 4 provided little contrast. Only approximate outlines were obtained for these specimens. Dissection was used to supplement the X-ray information. The swimbladder parameters were measured from the outlines, and results are in Table 2. "Length" gives fork length $L$; " $2 a$ " and " $2 b$ " give swimbladder length and maximum diameter, respectively; "Angle" gives the angle between the major swimbladder axis and a line from the fish snout to the tail; "Slices" gives the number of elements used for the cylinder model calculation; "Year" gives year of capture; "Condition" gives swimbladder condition as good or deflated.

The swimbladder to fish length ratio $2 a / L$ given in Table 2 is quite constant for all specimen except Pollock 3. The $b / a$ ratio of pollock is slightly larger than that of hake and is almost equal to that used by Furusawa ${ }^{15)}$ who points out that the scattering function is quite insensitive to the choice of this ratio.

TS measurements were made at approximately a twometer depth. The dimensions given in Table 2 have not been corrected for Boyle's law that would predict a swimbladder volume reduction of $20 \%$. Work by Mukai and Iida ${ }^{37)}$ suggests that a small reduction in TS would result.

The effect of number of slices is examined in Table 2 which shows the dorsal shape (a), horizontal shape (b), and calculated TS pattern (c) for the factors of $1 / 2,1,2$, and 5 of original slice number shown in Table 2 (for example, $19 \times 2$ means the original number of 19 and the factor of 2). The cubic interpolation method ${ }^{38)}$ is used to interpolate the width and height. As shown in Fig. 9(c), increasing the factor above 1 does not affect to the results seriously, so that further calculations are done using the factor 2 , as shown in Table 2.

Figure 10 compares measured and model based TS versus tilt angle for the fish we examined. The tilt angles of calculated patterns are shifted to match both measured and theoretical peaks. The measured data are shown as open circles. Dotted lines show the results from PSM with radii $2 a$ and $2 b$ from Table 2 . Bold lines are from the DCM. In Fig. 10(b) the dot-dash line represents the pattern for the
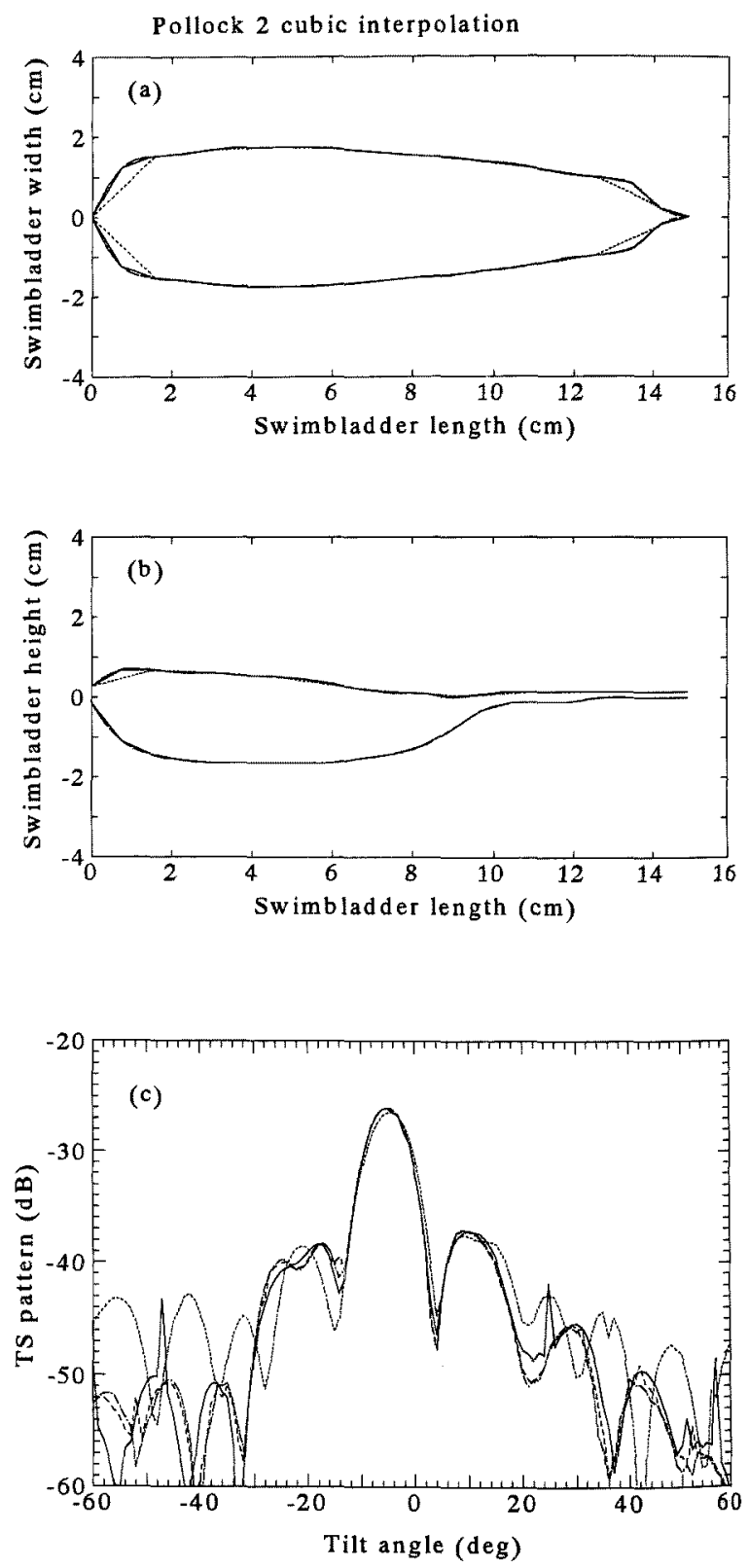

Fig. 9. The difference of the swimbladder shape and its modeled TS pattern of Pollock 2 when slice number is changed by the factor of $1 / 2$ (dot), 1 (solid), 2 (dash) and 5 (dot-dash) of the original number shown in Table 2. 


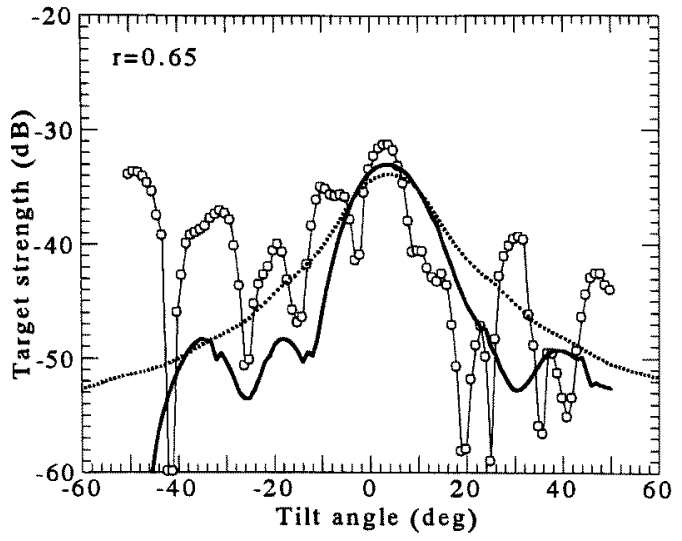

(a) Pollock1

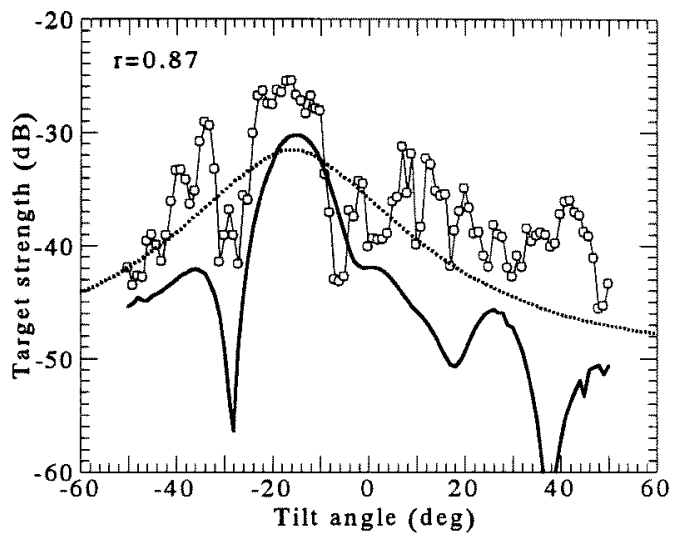

(c) Pollock3

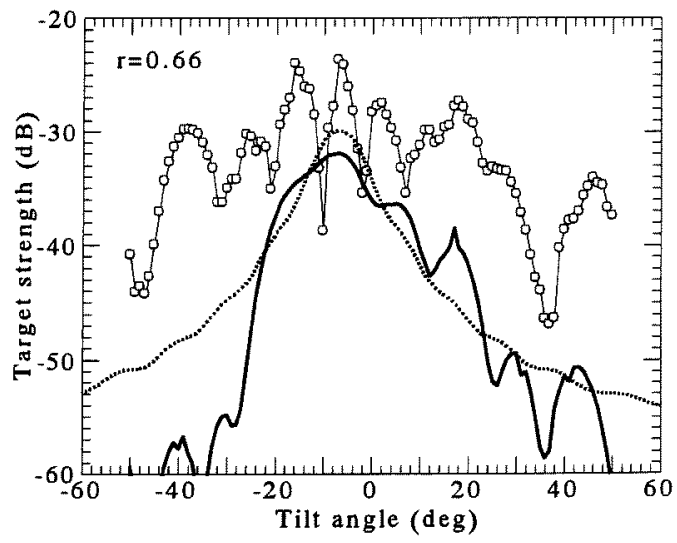

(e) Hake 1

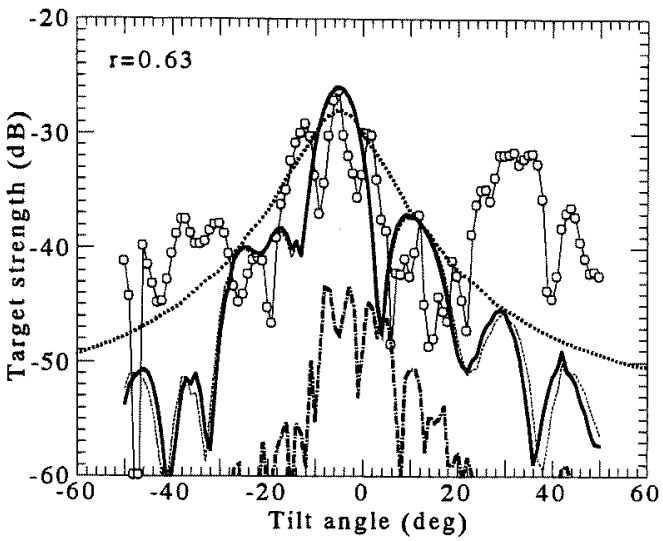

(b) Pollock2

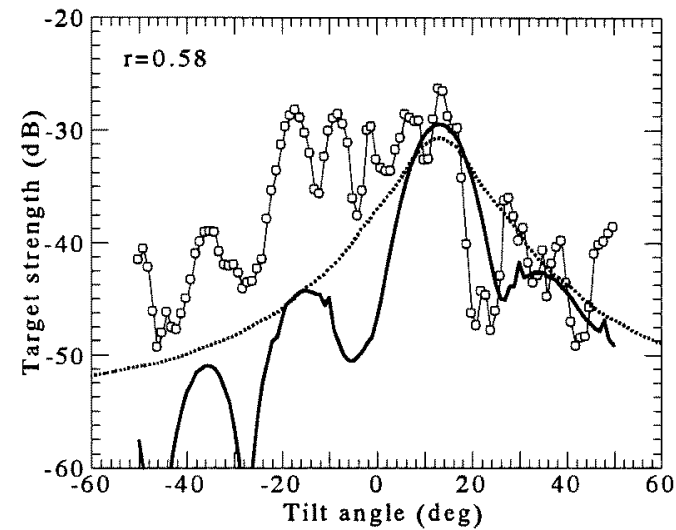

(d) Pollock4

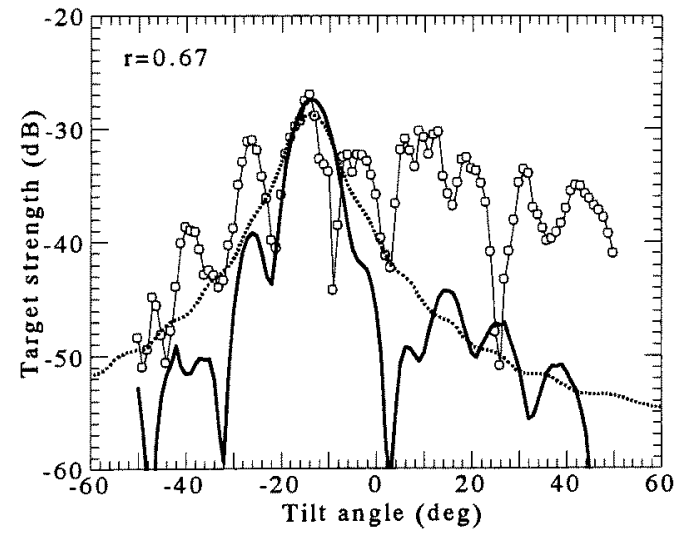

(f) $\mathrm{Hake} 2$

Fig. 10. The theoretical and measured TS values as functions or tilt angle.

Measurements are shown by circles and thin line. Results from PSM and DCM are shown by dotted line and bold line, respectively. Correlation coefficients, $r$, between DCM and measurement are shown. The dot-dash line for Pollock 2 is contribution from body.

body only obtained by liquid DCM (see Fig. 7) and the narrow solid line represents the pattern for the swimbladder in sea water. The correlation coefficient $r$ is given for corresponding DCM calculations and measurments, shown respectively in each figure.
The normalized maximum TS and the average TS are shown in Figs. 11(a) and 11(b), respectively, as a function of length divided by wavelength $(L / \lambda)$. Measurement, PSM, DCM are discriminated by symbols shown in the figure. 


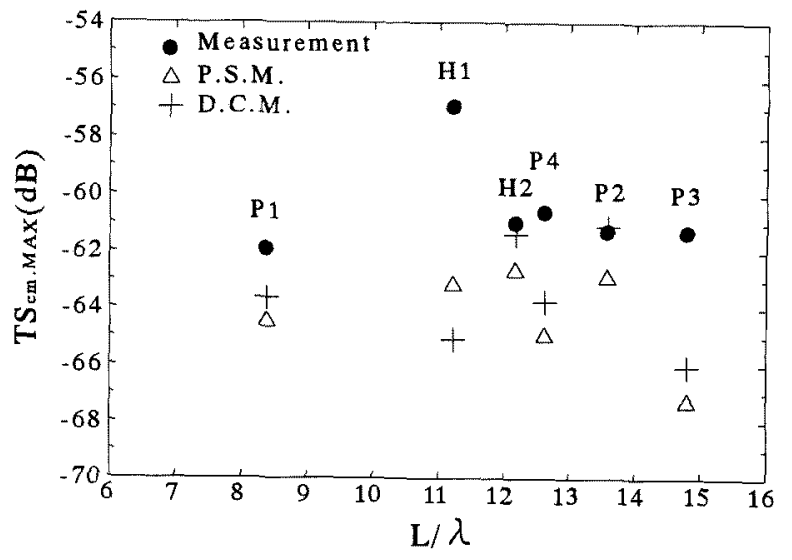

(a)Maximum TS

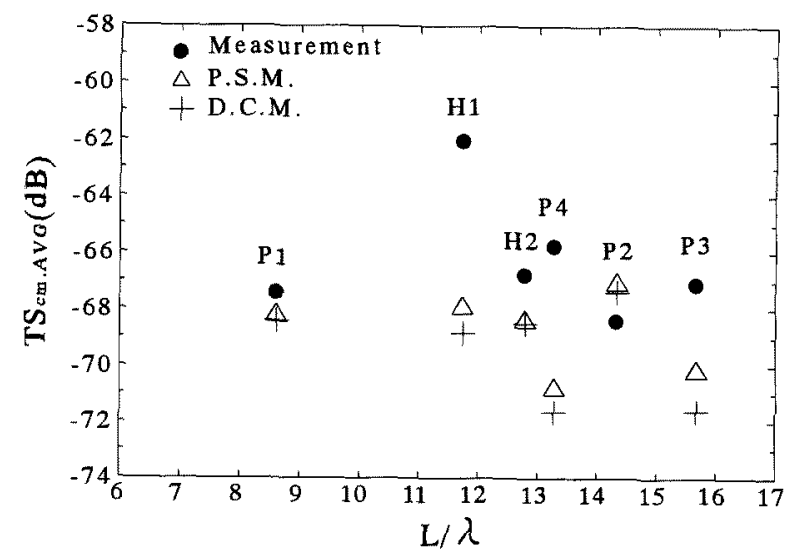

(b)Average TS

Fig. 11. (a) Maximum normalized $\mathrm{TS}\left(\mathrm{TS}_{\mathrm{Cm}, \mathrm{MAX}}\right)$ and (b) average normalized $T S\left(\mathrm{TS}_{\mathrm{cm}, A V_{\mathrm{G}}}\right)$ as a function of wavelength normalized length, $L / \lambda$.

The normalization is done by squared fork length in $\mathrm{cm}$.

As shown in Fig. 10, since the agreement between measurement and models is rather good for Pollock 2, TS patterns are calculated from a wider range of frequency using DCM. The results are shown in Fig. 12. The normalized maximum and the average TS versus frequency were calculated and are shown in Figs. 13(a) and 13(b) for pollock 2 and hake 2 , respectively. Circles show the measured data.

\section{Discussions}

\section{Comparison between Measurements and Modeling}

The agreement between measurements and modeling is moderate as shown in Fig. 10 and by attached correlation coefficient, but both models reproduce the general trend of the measured TS. The DCM shows the characteristic lobe structure. Correlation coefficients between DCM and PSM are $0.98,0.90,0.85,0.96,0.95$, and 0.97 in the case of Pollock 1, 2, 3, 4, Hake 1, and Hake 2, respectively. The agreement between PSM and DCM is rather good as was confirmed earlier by using the prolate spheroid shapes by Ye et al. ${ }^{21)}$

As for pollock 1, 2, and hake 2 the general pattern at low tilt angles is matched between theory and measurement, but the agreement deteriorates at large angles. The theoretical peaks are shifted by about $13^{\circ}$ in the patterns of Hake 2 in accordance with the measured peak. This shift does not agree with the angle offset, $6^{\circ}$, of the swimbladder shown in Table 2 . This might come from the fact that it is not easy to attach the fish even with its centerline in TS measurement and errors in reading swimbladder shapes from X-ray images. The agreement of the peak TS is poor for Pollock 3, and this suggests that the convention to use height for width is not a proper method. The experimental patterns of Pollock 4 and Hake 1 are considerably different from the modeled patterns.

The agreement between measurements and models is only moderate. The most serious reason is thought to be that the clear shape of the swimbladder could not be observed for these large specimens and there should be a difference between the actual shape, which governs experiment, and the reproduced shape which governs the modelings. Actually, a similar technique has achieved excellent agreement between the theory and the experiment for clearer swimbladder shape of smaller fresh water fish, Ayu Plecoglossus altivelis. ${ }^{* 5}$ Therefore, to make the TS prediction technique using $\mathrm{X}$-ray and modeling accurate, improved X-ray photographic technique is necessary.

The second plausible reason of the moderate agreement is that both models assume that the cross-sections are circular, but actual cross-sections are not as seen in Fig. 6 . The process of catching, freezing, transporting, restoring, thawing, and manipulating for the measurements might change the swimbladder to a flattened shape, although the last was examined to be not serious by the $X$-ray inspections.

More detailed realization is performed by Kirchhoff approximation for many facets of the bladder surface, ${ }^{14)}$ but sophisticated specimen and data manipulation is necessary. ${ }^{3)}$

\section{Contribution from Body}

We have neglected so far the contribution from the fish body based on the knowledge of the past studies cited above. Here we confirm this using DCM which can be also used for a liquid deformed cylinder. Applying the liquid model for the body of Pollock 2 shown in Fig. 7, the TS pattern shown by the dot-dash line in Fig. 10(b) is obtained. As seen, the body contribution is less than $10 \mathrm{~dB}$ except certain angles and the bold line and the narrow solid line in Fig. 10(b) are almost the same, our assumption is reasonable to see the approximate trend of TS pattern of individual fish.

Therefore, it is sufficient to consider only the swimbladder and we can use a freshwater tank for measurement of sea fish with a swimbladder.

\section{On Modeling}

There are several models for fish TS and they have their

*5 K. Sawada et al.: Experimental verification of the deformed cylinder scattering model and its application to the calculation of backscattering from fish. International Congress on Acoustics, Seattle, June 20-26, 1998. 


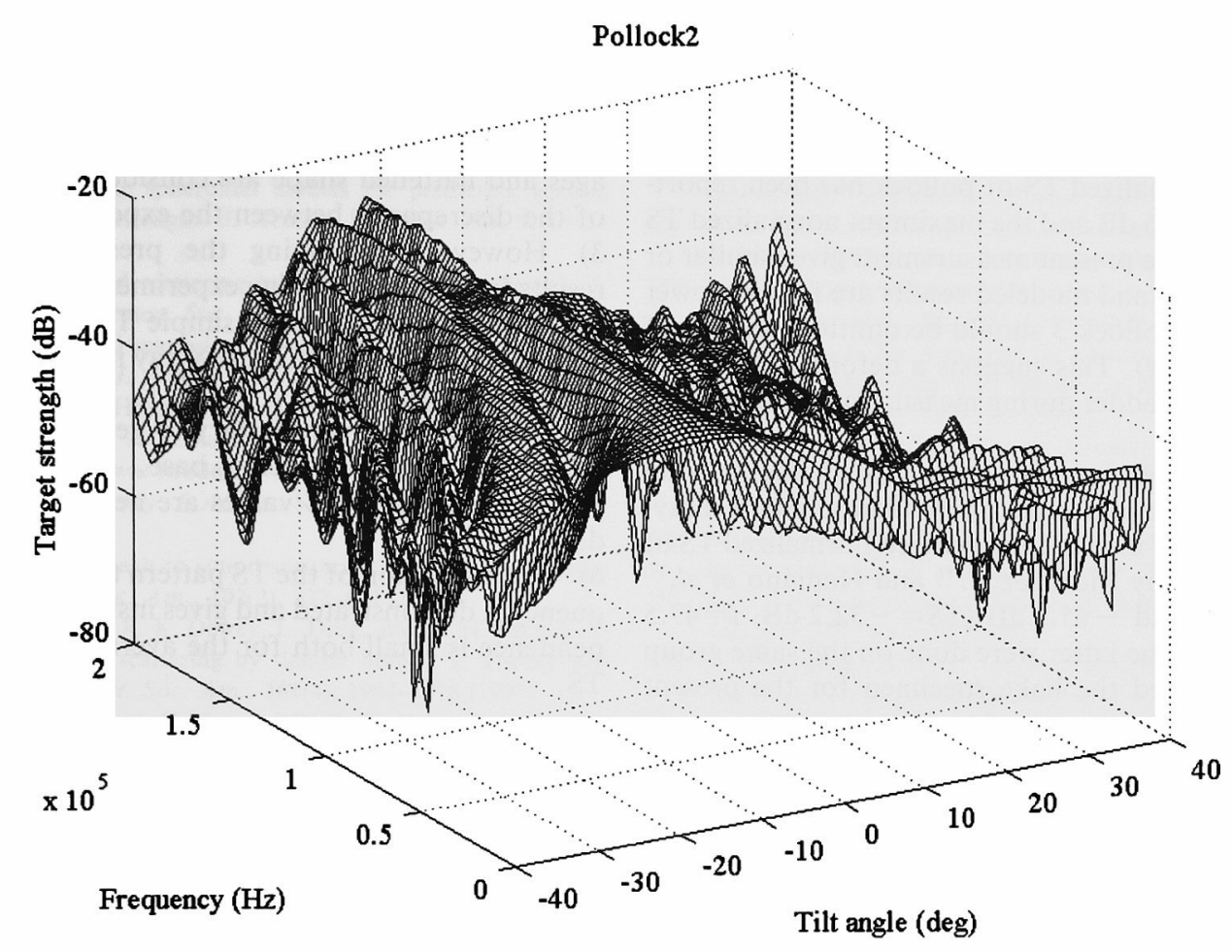

Fig. 12. Calculated TS pattern of Pollock 1 over a broad frequency range.

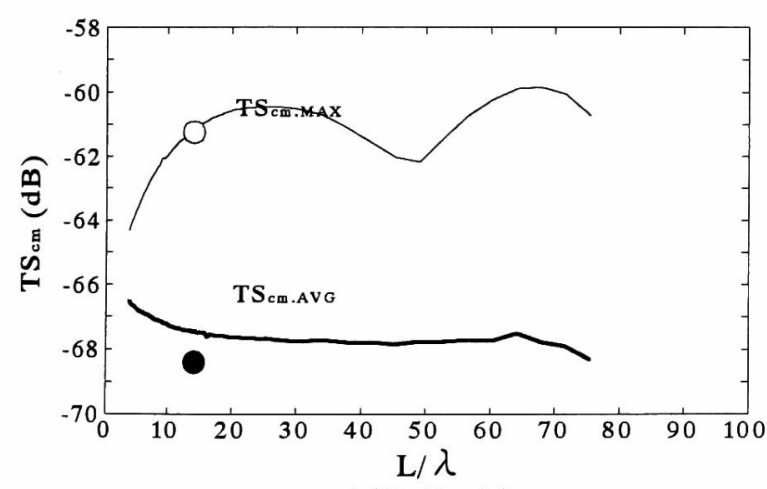

(a)Pollock2

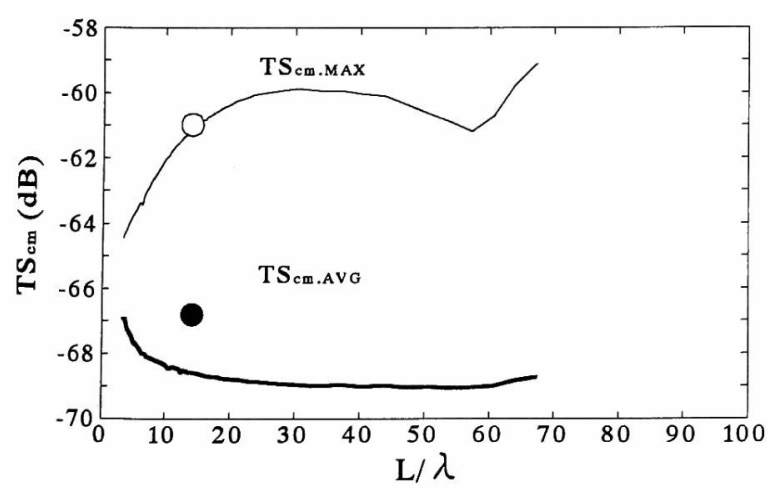

(b)Hake2

Fig. 13. Frequency characteristics of average $\left(\mathrm{TS}_{\mathrm{cm}, \mathrm{AVG}}\right)$ and maximum $\left(\mathrm{TS}_{\mathrm{cm}, \mathrm{MAX}}\right)$ target strength normalized by squared fork length in $\mathrm{cm}$ for Pollock 2 (upper) and Hake 2 (lower).

Circles show measurements. own merits and demerits. Therefore, we could not judge the models from one aspect. We have used PSM and DCM.

The PSM is exact, is applicable to a broad parameter range, and needs few parameters. Therefore, it is suitable to elucidate general trends of TS of marine animals ${ }^{15)}$ and also can be a standard in developing other more theoretically approximate model. ${ }^{21)}$ One example of the outcomes is shown in Fig. 11 and Fig. 13 where the normalized TS are shown as a function of $L / \lambda$. If $f$ in Eq. (2) is divided by the length $(L=2 a)$, then $k$ in the right side becomes $k a$ or $L / \lambda$ eliminating pure length dependency and establishing the similarity law. This double normalization scheme is thus theoretically justified by PSM and very effective in processing and displaying data. In regeneration of the individual TS pattern for individual shape, however, this model gives a poorer result than other more detailed models such as the present DCM. In Fig. 10, however, we can confirm how well the PSM expresses the general trend of the DCM.

The DCM model ${ }^{21)}$ we have used is more suitable for individual fish and better for the present study than PSM as shown in Fig. 10. This model can predict scattering characteristics for rather complicated shapes by moderate number of parameters and is applicable to a wider range of parameters, as shown in Fig. 12. This model, however, could not predict scattering properties at large tilt angle and cross sections along the axis need to be circular. We believe that the present DCM model is useful for fish TS prediction by X-ray and modeling technique, if a good quality X-ray photo is obtained. 


\section{Comparison of Target Strength Values}

We have some literature describing walleye pollock ${ }^{4,11-13)}$ and hake ${ }^{13,27,39), * 6}$ Our present data (see Fig. 11) are compared with the past data.

The average normalized TS of pollock has been reported to be around $-66 \mathrm{~dB}$ and the maximum normalized TS around $-60 \mathrm{~dB}$. The present measurement gives similar or 1-2 dB lower values and modeled results are further lower by about 1-3 dB (Pollock 3 should be omitted because of lack of dorsal image). This suggests a deformed flattened shape of the swimbladder during measurement rather than natural shape.

There are relatively few measurements of Pacific hake TS. However, those reported by Williamson and Traynor ${ }^{39)}$ and Traynor ${ }^{13)}$ indicate an averaged normalized TS of $-68 \mathrm{~dB}$ and those by Kieser et al. ${ }^{* 6}$ and Hamano et al. ${ }^{27)}$ indicate $-66 \mathrm{~dB}$ and $-65.7 \mathrm{~dB}(T S=-32.2 \mathrm{~dB}, l=47.5$ $\mathrm{cm}$ ), respectively. The latter were done on the same group of fish that provided the hake specimen for the present work.

The averaged normalized TS of Hake 1 and Hake 2 is -62.1 and $-66.8 \mathrm{~dB}$, respectively in our measurement. The value of Hake 2 is close to the ones measured by Kieser et al. ${ }^{* 6}$ and Hamano et al. ${ }^{27)}$ However, that of Hake 1 is much larger.

An averaged normalized TS of $-68 \mathrm{~dB}$ is currently used for stock assessment purposes ${ }^{40}$ but there is an obvious need for additional TS information. We should collect more TS data for hake to discuss this more synoptically as is done by Traynor ${ }^{13)}$ for walleye pollock.

\section{Future Works}

The promising results in this study has encouraged us to do another similar trial for a more tractable object fish, Ayu, and excellent agreement with measurement and theory is obtained as mentioned above. Combining this fact, the present method for TS prediction using $X$-ray and DCM model will be a good simple method. We only need good quality X-ray images and a program realizing Eq. (4). We do not have much experience, however, for this method, and more examination is necessary, especially for larger marine fish.

For the success of the present method, the X-ray image should be clear and regenerate the in situ shape of the swimbladder. In the Ayu experiment, an anesthetized specimen was used for X-ray photographing. It is not easy to get good quality X-ray image for large marine fish, especially hake, and some device is necessary. Recent medical imaging techniques such as $\mathrm{NMR}^{41)}$ or $\mathrm{X}$-ray Computer Tomography may be promising to obtain a detailed description of the swimbladder that is required for detailed models such as the present DCM and the Kirchhoff model. Taking an X-ray system on board a research vessel will be one resolution to obtain the in situ shape of the swimbladder.

In summary we have learned the following:

1) It should be said that specimen qualities, including natural undamaged swimbladders, are an important prerequisite both for precise measurement and calculation. Figure 10 shows that the best results are from pollock 2 and hake 2. These also have the best looking swimbladders (Fig. 6).

2) The agreement between measured and theoretical fish TS is moderate. The difficulty to get high quality X-ray images and flattened shape are considered to be the reasons of the discrepancy between the experiment and theory. 3) However, combining the present results and the results from the succeeding experiment using a more tractable fish, Ayu, the present simple TS prediction method, that is, applying the DCM to X-ray image of swimbladder, is promising method.

4) Further effort is necessary to get natural and clear $X$ ray images for the modeling base.

5) The measured TS values are nearly equal to the past data.

6) Extrapolation of the TS pattern to a wider range of frequency is demonstrated and gives insight that frequency dependence is small both for the average TS and maximum TS.

Acknowledgments The work is supported by grants from the Science and Technology Agency of Japan and by Japan Science and Technology Grant from the Canadian Department of External Affairs. The former provided support for a research visit of one of the authors (ZY) to Japan. Dr. Akira Hamano kindly provided the Pacific Hake specimen.

The authors thank anonymous referees for their suggestions to improve this study.

\section{References}

1) D. N. MacLennan and E. J. Simmonds: Fisheries Acoustics, Chapman and Hall, London, 1991, pp. 164-200.

2) O. Nakken and $K$. Olsen: Target strength measurements of fish. Rapp. P.-v. Reun. Cons. int. Explor. Mer, 170, 52-69 (1977).

3) K. G. Foote and E. Ona: Swimbladder cross sections and acoustic target strength of 13 pollack and 2 saithe. Fiskeridir. Skr. Ser. Havunders., 18, 1-57 (1985).

4) Y. Miyanohana, K. Ishii, and M. Furusawa: Measurements and analyses of dorsal-aspect target strength of six species of fish at our frequencies. Rapp. P.-v. Reun. Cons. int. Explor. Mer., 189, 317-324 (1990).

5) K. A. Johannesson and G. F. Losse: Methodology of acoustic estimations of resource survey projects. Rapp. P.-v. Reun. Cons, int. Explor. Mer., 170, 296-318 (1997).

6) J. I. Edwards and F. Armstrong: Measurement of the TS of live herring and mackerel. FAO Fish. Rep. 300, 69-77 (1983).

7) J. E. Ehrenberg, T. J. Carlson, J. J. Traynor, and N. J. Williamson: Indirect measurement of the mean acoustic backscattering cross section of fish. J. Acoust. Soc. Am., 69(4), 955-962 (1981).

8) B. J. Robinson: An in situ technique to determine fish target strength with results for blue whiting. J. Cons. Int. Explor. Mer. CIEM. 40, 53-160 (1982).

9) J. J. Traynor and J. E. Ehrenberg. (1979): Evaluation of the dual beam acoustic fish target strength measurement method. J. Fish. Res. Bd. Can., 36(9), 1065-1071 (1979).

10) J. J. Traynor and J. E. Ehrenberg: Fish and standard-sphere targetstrength measurements obtained with a dual-beam and split-beam echo sounding system. Rapp. P.-v. Reun. Cons. int. Explor. Mer., 189, 325-335 (1990).

11) J. J. Traynor and N. J. Williamson: Target strength measurements of walleye pollock (Theragra chalcogramma) and a simulation study of the dual beam method. FAO Fish. Rep., 300, 112-123 (1983).

12) K. G. Foote and J. J. Traynor: Comparison of walleye pollock target strength estimates determined from in situ measurements and calculations based on swimmbladder form. J. Acoust. Soc. Am.,

\footnotetext{
${ }^{*}$ R. Kieser et al.: The analysis of target strength measurements, Strait of Georgia, February-March, 1996. Internal report. 20p and Appendix.
} 
83, 9-17 (1988)

13) J. J. Traynor: Target strength measurements of walleye pollock and Pacific whiting. ICES J. Mar. Sci., 53, 253-258 (1996).

14) K. G. Foote: Rather high frequency sound scattering by swimbladder fish. J. Acoust. Soc. Am., 78, 688-700 (1985).

15) M. Furusawa: Prolate spheroidal models for predicting general trends of fish target strength. J. Acoust. Soc. Jpn. (E), 9, 13-24 (1988).

16) T. K. Stanton: Sound scattering by cylinders of finite length. I. Fluid cylinders. J. Acoust. Soc. Am., 83, 55-63 (1988).

17) T. K. Stanton: Sound scattering by cylinders of finite length. III. Deformed cylinders. J. Acoust. Soc. Am., 86, 691-705 (1989).

18) C. S. Clay and J. K. Horne: Acoustic models of fish: The Atlantic cod (Gadus morhua). J. Acoust. Soc. Am., 96, 1661-1668 (1994).

19) Z. Ye and M. Furusawa: Modeling of target strength of swimbladder fish at high frequency. J. Acoust. Soc. Jpn. (E), 16(6), 371-379 (1995).

20) Z. Ye: A novel approach to sound scattering by cylinders of finite length. J. Acoust. Soc. Am., 102(2), 877-884 (1997).

21) Z. Ye, E. Hoskinson, R. K. Dewey, L. Ding, and D. M. Farmer: A method for acoustic scattering by slender bodies. I. Theory and verification. J. Acoust. Soc. Am., 102(4), 1964-1976 (1997).

22) S. McClatchie, J. Alsop, Z. Ye, and R. F. Coombs: Consequence of swimbladder model choice and fish orientation to target strength of three New Zealand fish species. ICES J. Mar. Sci., 53, 847-862 (1996).

23) K. G. Foote: Maintaining precision calibrations with optimal copper spheres. J. Acoust. Soc. Am., 73, 1054-1063 (1983).

24) C. S. Clay and H. Medwin: Acoustical Oceanography, Willy \& Sons, New York, 1977, pp. 153-155.

25) K. Sawada, Y. Miyanohana, and K. Ishii: Precise target strength pattern measurement in an indoor tank. J. Acoust. Soc. Jp. (E), 18(5), 231-238 (1997).

26) M. Furusawa, Y. Takao, K. Sawada, T. Oukubo, and K. Yamatani: Versatile echo sounding system using dualbeam. Nippon Suisan Gakkaishi, 59, 967-980 (1993).

27) A. Hamano, T. Sasakua, R. Kieser, K. Cooke, K. Kubota, and A. Clay: Target-strength measurements of Pacific hake (Merluccius productus) in Canadian waters using quasi-ideal and conventional beam transducers. ICES J. Mar. Sci., 53(2), 273-280 (1996).

28) K. G. Foote: Importance of the swimbladder in acoustic scattering by fish. J. Acoust, Soc. Am., 67, 2084-2089 (1980)

29) D. M. Nash, Y. Sun, and C. S. Clay: High resolution acoustic structure of fish," J. Cons. int. Explor. Mer., 43, 21-31 (1987).

30) Z. Ye and D. M. Farmer: Acoustic scattering by fish in the forward direction. ICES J. Mar. Sci, 53(2), 249-252 (1996)

31) M. C. Junger: Scattering by slender bodies of revolution. $J$. Acoust. Soc. Am., 72, 1954-1956 (1982).

32) L. Ding and Z. Ye: A method for acoustic scattering by slender bodies. II. Comparison with laboratory measurements. J. Acoust. Soc. Am., 102(4), 1977-1981 (1997).

33) C. Partridge and E. R. Smith: Acoustic scattering from bodies: Range of validity of the deformed cylinder method. $J$. Acoust. Soc. Am., 97, 784-795 (1995)

34) M. Furusawa, K. Ishii, and Y. Miyanohana: Attenuation of sound by schooling fish. J. Acoust. Soc. Am., 92, 987-994 (1992)

35) K. G. Foote: Averaging of fish target strength functions. J. Acoust. Soc. Am., 67, 504-515 (1980).

36) Y. Miyanohana, K. Ishii, and M. Furusawa: Effect of beam pattern and fish behavior on averaged target strength. Bull. Nat. Res. Fish. Eng., 7, 87-96 (1986) (in Japanese).

37) T. Mukai and K. Iida: Depth dependence of target strength of live kokanee salmon in accordance with Boyle's law. ICES J. Mar. Sci., 53, 245-248 (1996).

38) R. G. Keys: Cubic convolution interpolation for digital image processing. IEEE Trans. On Acoustics, speech, and signal processing, 29(6), 1153-1160 (1981).

39) N. J. Williamson and J. J. Traynor: In situ target strength estimation of Pacific Whiting, Meriuccius productus, using a dual beam transducer. J. Cons. Int. Explor. Mer., 41, 253-292 (1984).

40) M. W. Dorn: Status of the coastal Pacific whiting resource in 1996 Alaska Fisheries Science Center, NMFS, NOAA, Seattle.

41) S. Seri, T. Watanabe, M. Maita, N. Okamoto, Y. Hashiguchi, C. Fujimoto, and K. Iwai: Application of magnetic resonance imaging to fishes. Nippon Suisan Gakkaishi, 61, 331-338 (1995). 